\title{
A covalent organic framework-based multifunctional therapeutic platform for enhanced photodynamic therapy via catalytic cascade reactions
}

\author{
Lihan $\mathrm{Cai}^{1,2}$, Chunling $\mathrm{Hu}^{1,2}$, Sainan Liu ${ }^{1,2}$, Ying Zhou ${ }^{1}$, Maolin Pang ${ }^{1,2^{*}}$ and Jun Lin $^{1,2,3^{*}}$
}

\begin{abstract}
Utilizing the unique tumor microenvironment (TME) to conduct chemical reactions for cancer treatment becomes a hot topic recently. Nevertheless, single chemical reaction in TME is often restricted by scanty reaction substrates and slow reaction rate. Meanwhile, the toxic substances produced by the reactions are usually not enough to kill cancer cells. Herein, using covalent organic frameworks (COFs) as the template, Au nanoparticles (Au NPs) were subsequently grown on the surface of the COF, then a thin layer of manganese dioxide $\left(\mathrm{MnO}_{2}\right)$ was coated over the material, and finally hyaluronic acid (HA) was introduced to improve the biocompatibility. The resultant product, named COF-Au$\mathrm{MnO}_{2}$, was involved in several processes to form cascade reactions in the TME. Specifically, under hypoxic conditions, COF-Au- $\mathrm{MnO}_{2}$ could react with intratumoral $\mathrm{H}_{2} \mathrm{O}_{2}$ to produce $\mathrm{O}_{2}$ to enhance the type II photodynamic therapy (PDT), and Au NPs could decompose glucose to promote starving-like therapy. Besides, starving-like therapy can also produce $\mathrm{H}_{2} \mathrm{O}_{2}$ to increase $\mathrm{O}_{2}$ production. Simultaneously, $\mathrm{MnO}_{2}$ can consume glutathione (GSH) to enhance the antitumor efficacy, and the released $\mathrm{Mn}^{2+}$ could be used for $T_{1}$-weighted magnetic resonance imaging (MRI). Both in vitro and in vivo experiments had proven excellent cancer cell killing effect and antitumor efficacy of $\mathrm{COF}-\mathrm{Au}-\mathrm{MnO}_{2}$ via such a cycle-like process.
\end{abstract}

Keywords: covalent organic framework, cascade reaction, tumor microenvironment, enhanced photodynamic therapy

\section{INTRODUCTION}

Tumor microenvironment (TME) [1,2], including hypoxia, overproduced $\mathrm{H}_{2} \mathrm{O}_{2}$, mild acidity and elevated glutathione $(\mathrm{GSH})$ content, severely reduced the effectiveness of several reactive oxygen species (ROS)-related cancer treatment modalities, such as chemodynamic therapy (CDT), sonodynamic therapy (SDT) and photodynamic therapy (PDT), etc. [3]. Hence, how to alleviate the TME or use the TME to kill cancer cells has become a hot topic recently [4-6].

Fortunately, researchers have achieved the goal by using the toxic substances in the TME to kill cancer cells [7]. For example, ROS, which mainly include hydroxyl radical $(\cdot \mathrm{OH})$, singlet oxygen $\left({ }^{1} \mathrm{O}_{2}\right)$ and superoxide radical $\left(\cdot \mathrm{O}^{2-}\right)$, were used to kill cancer cells [8]. However, the ROS-related cancer treatment modalities are highly dependent on the oxygen level in the TME [9]. Therefore, in order to enhance the antitumor efficacy, simultaneously alleviating the hypoxia condition, reducing the GSH content and increasing the $\mathrm{H}_{2} \mathrm{O}_{2}$ concentration are quite important [8]. It is well known that large amounts of hydrogen peroxide $\left(\mathrm{H}_{2} \mathrm{O}_{2}\right)$ were produced in the tumor with the help of superoxide dismutase (SOD), which is one of the important features of solid tumors. The overexpressed $\mathrm{H}_{2} \mathrm{O}_{2}$ could be used for SDT or PDT by providing endogenous ROS [1]. Nevertheless, the amount of $\mathrm{H}_{2} \mathrm{O}_{2}$ inside the tumor is about $50 \times 10^{-6}$ $-100 \times 10^{-6} \mathrm{~mol} \mathrm{~L}^{-1}$, which is not enough to produce endogenous oxygen to improve the efficiency of PDT or SDT [10]. Recently, it has been reported that some metal nanoparticles possess enzyme-mimic catalytic properties [11-13]. For example, Au nanoparticles (NPs) are quite similar to glucose oxidase (GOx), which could be used in oxidizing glucose to produce $\mathrm{H}_{2} \mathrm{O}_{2}$ in the presence of oxygen [14]. Manganese dioxide $\left(\mathrm{MnO}_{2}\right)$ can react with

\footnotetext{
${ }^{1}$ State Key Laboratory of Rare Earth Resource Utilization, Changchun Institute of Applied Chemistry, Chinese Academy of Sciences, Changchun 130022, China

${ }^{2}$ University of Science and Technology of China, Hefei 230026, China

${ }^{3}$ School of Applied Physics and Materials, Wuyi University, Jiangmen 529020, China

* Corresponding authors (emails: mlpang@ciac.ac.cn (Pang M); jlin@ciac.ac.cn (Lin J))
} 
$\mathrm{H}_{2} \mathrm{O}_{2}$ to produce oxygen under the slightly acidic conditions of the tumor [15-19], and the released $\mathrm{Mn}^{2+}$ could be used as a contrast agent for $T_{1}$-weighted magnetic resonance imaging (MRI) [20-22].

Covalent organic frameworks (COFs) are a kind of porous crystalline materials connected by covalent bonds [23]. Due to the advantages like adjustable pore size, excellent thermal stability and large porosity, COFs have been applied in many research fields like catalysis, gas storage and separation, etc. [24]. However, the application of COFs in biomedical fields is still in its early stage [25-32]. Recently, we have found that COFs could be used as photosensitizers for photodynamic cancer therapy [30]. Hence, it can be anticipated that by introducing artificial enzymes, such as metal nanoparticles and metal oxide, enough oxygen will be generated through cascade reactions and the photodynamic effect could be greatly enhanced via a synergistic effect. In this study, a COF$\mathrm{Au}-\mathrm{MnO}_{2}$-based therapeutic agent was designed for the augmented PDT and starving-like therapy. Specifically, the COF based on 1,3,5-tris(4-aminophenyl)benzene (TAPB) and 2,5-dimethoxyterephthaldehyde (DMTP) was prepared at room temperature via a simple solutionbased method [26]. Due to the presence of abundant amino groups in the COF, the in-situ formed Au NPs were easily attached on the surface of the highly uniform COF nanospheres, and subsequently, a thin layer of $\mathrm{MnO}_{2}$ was deposited, which was formed by the reaction between potassium permanganate and amino groups.
After that, in order to improve the biocompatibility, hyaluronic acid (HA) was coated on the surface through electrostatic adsorption [33-38]. Finally, the in vitro cancer cell killing effect and in vivo antitumor efficacy were evaluated (Scheme 1).

\section{EXPERIMENTAL SECTION}

\section{Materials}

DMTP $\left(\mathrm{C}_{10} \mathrm{H}_{10} \mathrm{O}_{4}\right.$, AR, 97\%, Jilin Chinese Academy of Sciences-Yanshen Technology Co., Ltd.), TAPB $\left(\mathrm{C}_{24} \mathrm{H}_{21}\right.$ $\mathrm{N}_{3}, \mathrm{AR}, 98 \%$, Alpha), acetic acid $\left(\mathrm{CH}_{3} \mathrm{COOH}, \mathrm{AR}, 99.5 \%\right.$, Beijing Chemical Works), acetonitrile $\left(\mathrm{CH}_{3} \mathrm{CN}, 99.8 \%\right.$, Vetec), ethanol (AR, Beijing Chemical Works), hydrogen tetrachloroaurate (III) hydrate $\left(\mathrm{HAuCl}_{4} \cdot 4 \mathrm{H}_{2} \mathrm{O}, 99.9 \%\right.$, Strem Chemicals), sodium borohydride $\left(\mathrm{NaBH}_{4}, \mathrm{AR}\right.$, $98 \%$, Aldrich), trichloroacetic acid $\left(\mathrm{C}_{2} \mathrm{HCl}_{3} \mathrm{O}_{2}, 99.9 \%\right.$, Aladdin), HA (97\%, Macklin), hydroxylamine solution $\left(\mathrm{NH}_{2} \mathrm{OH}, 50 \%\right.$, Aladdin), potassium permanganate $\left(\mathrm{KMnO}_{4}\right)$, glutathione (reduced) $\left(\mathrm{C}_{10} \mathrm{H}_{17} \mathrm{~N}_{3} \mathrm{O}_{6} \mathrm{~S}, 98 \%\right.$, Aladdin), and glucose $\left(\mathrm{C}_{6} \mathrm{H}_{12} \mathrm{O}_{6}, 80 \%\right.$, Macklin) were used as received.

\section{Synthesis of COF}

DMTP $(3 \mathrm{mg}, \quad 0.018 \mathrm{mmol})$ and TAPB $(3 \mathrm{mg}$, $0.0084 \mathrm{mmol}$ ) were dissolved in $3 \mathrm{~mL}$ of acetonitrile separately, and then the two solutions were mixed. Subsequently, $0.15 \mathrm{~mL}$ of acetic acid was added and the mixture was stirred at room temperature for $12 \mathrm{~h}$. The precipitate

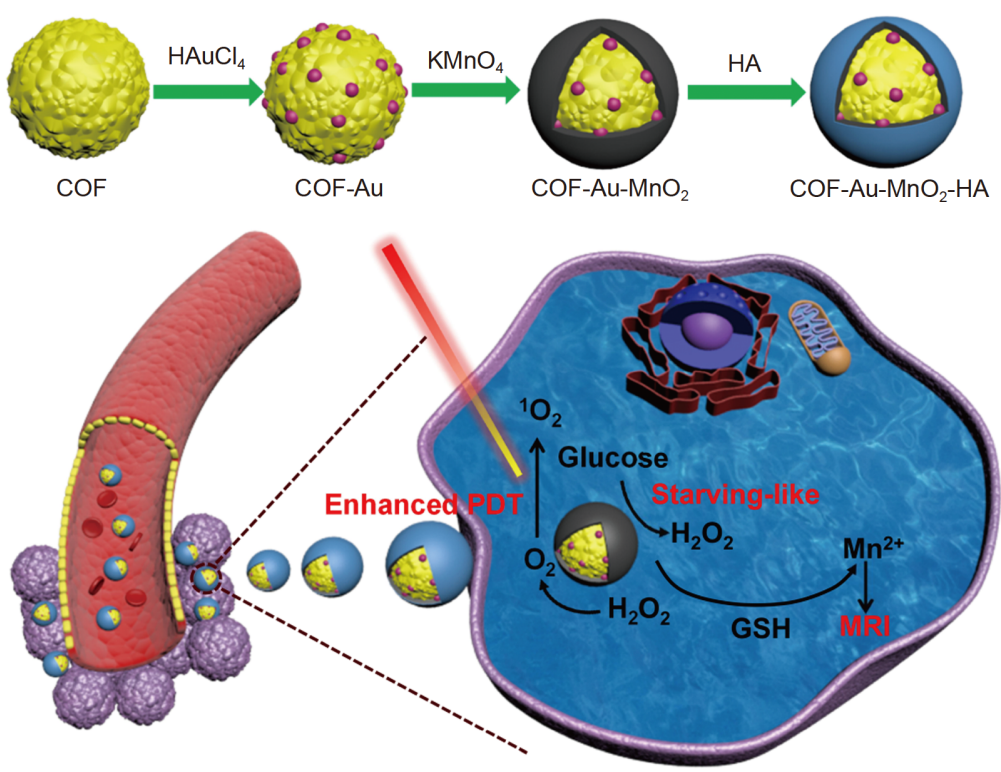

Scheme 1 Schematic illustration of the synthetic process of COF-Au- $\mathrm{MnO}_{2}-\mathrm{HA}$ and the therapeutic mechanism. 
was collected by centrifugation and washed with ethanol for three times.

\section{Synthesis of COF-Au}

COF (3 mg) was mixed with $\mathrm{HAuCl}_{4} \quad(0.6 \mathrm{~mL}$, $\left.1.5 \mathrm{mg} \mathrm{mL}^{-1}\right)$ and stirred for $4 \mathrm{~h}$. A NaBH $4\left(2 \mathrm{mg} \mathrm{mL}^{-1}\right.$, $0.6 \mathrm{~mL}$ ) solution was added into the above solution. After being stirred for $1 \mathrm{~h}$, the precipitate was collected by centrifugation and washed with deionized water.

\section{Synthesis of $\mathrm{COF}-\mathrm{Au}-\mathrm{MnO}_{2}$}

COF-Au (3 mg) was mixed with $\mathrm{KMnO}_{4}(0.6 \mathrm{~mL}$, $10 \mathrm{mg} \mathrm{mL}^{-1}$ ) and stirred for $6 \mathrm{~h}$. The precipitate was collected by centrifugation and washed with deionized water.

\section{Modification of the as-synthesized products with $\mathrm{HA}$} COF-Au- $\mathrm{MnO}_{2}(10 \mathrm{mg})$ was mixed with $\mathrm{HA}(5 \mathrm{mg})$ in $5 \mathrm{~mL}$ of deionized water. After being stirred for $12 \mathrm{~h}$, the precipitates were collected by centrifugation and washed with anhydrous ethanol several times. All the experiments were carried out at room temperature.

\section{In vivo cascades reaction-based antitumor therapy}

Female Balb/c mice were purchased from the Center of Experimental Animals, Jilin University. All animal studies were conducted in accordance with the guidelines of the National Regulation of China for Care and Use of Laboratory Animals. The 4T1 tumor models were successfully established by subcutaneous injection of $4 \times 10^{6}$ cells suspended in $100 \mu \mathrm{L}$ of phosphate buffered saline (PBS) into the left axilla of each mouse. The mice were treated when the tumor volumes reached $80-100 \mathrm{~mm}^{3}$. The tumor-bearing mice were randomly divided into eight groups ( $n=6$, each group), and treated with (1) PBS, (2) PBS under $650 \mathrm{~nm}$ laser irradiation, (3) COF-HA, (4) COF-Au-HA, (5) COF-Au- $\mathrm{MnO}_{2}-\mathrm{HA}$, (6) COF-HA under $650 \mathrm{~nm}$ laser irradiation, (7) COF-Au-HA under $650 \mathrm{~nm}$ laser irradiation, and (8) COF-Au- $\mathrm{MnO}_{2}-\mathrm{HA}$ under $650 \mathrm{~nm}$ laser irradiation. Nanomaterials were injected by in situ injection, and each injection dose was $100 \mu \mathrm{L}$ at a concentration of $1 \mathrm{mg} \mathrm{mL}^{-1}$. For group (2), (6), (7) and (8), the tumors were exposed to a $650 \mathrm{~nm}$ laser $\left(0.5 \mathrm{~W} \mathrm{~cm}^{-2}\right)$ for $10 \mathrm{~min}$ after $12 \mathrm{~h}$ post-injection. The body weight and tumor volume of each mouse were monitored every two days, and after 14 days treatment, the tumors were dissected and weighed to evaluate the therapeutic efficacy. In a typical calculation, the tumor volume was calculated by $V=$ length $\times$ width $^{2} / 2$. The relative tumor volume was calculated as $V / V_{0}$, where $V_{0}$ was the tumor volume before the treatment. Finally, the major organs, such as liver, spleen, heart, lung, and kidney, were removed and fixed in $4 \%$ paraformaldehyde solution for histological examination in order to further investigate the biocompatibility of COF-Au- $\mathrm{MnO}_{2}-\mathrm{HA}$.

\section{RESULTS AND DISCUSSION}

Details for characterization of the materials are provided in the Supplementary information. Fig. 1a-c and Fig. S1 show the transmission electron microscopy (TEM) and scanning electron microscopy (SEM) images of COF, COF-Au and COF-Au- $-\mathrm{MnO}_{2}$, respectively. As shown in Fig. 1a and Fig. S1a, spherical COF NPs with a uniform size of $200 \mathrm{~nm}$ were successfully synthesized by the room temperature solution-based method. Au NPs with sizes around $3 \mathrm{~nm}$ were prepared by reducing chloroauric acid with $\mathrm{NaBH}_{4}$ and decorated on the surface of COF (Fig. 1b). Finally, the resultant $\mathrm{COF}$ and Au were encapsulated by a layer of $\mathrm{MnO}_{2}$ (Fig. 1c) [17]. The elemental mapping and energy-dispersive X-ray spectroscopy (EDS) results indicated the presence of $\mathrm{Au}$ and $\mathrm{MnO}_{2}$ (Fig. $1 \mathrm{~d}-\mathrm{i}$ and Fig. S2) $[10,39]$. According to the inductively coupled plasma (ICP) result, the contents of $\mathrm{Au}$ and $\mathrm{MnO}_{2}$ were about $4.5 \%$ and $26.1 \%$, respectively. The X-ray diffraction (XRD) patterns demonstrated that $\mathrm{COF}$ and Au were obtained (Fig. S3). It should be noted that the spherical morphology of COF was still maintained after being coated with $\mathrm{Au}, \mathrm{MnO}_{2}$ and $\mathrm{HA}$; however, the hydrodynamic size of the resultant product was steadily increased, and the corresponding zeta potentials were changed (Figs S4, S5 and Table S1) [34]. Meanwhile, excellent stability was found for $\mathrm{COF}-\mathrm{Au}-\mathrm{MnO}_{2}-\mathrm{HA}$ after being immersed in $\mathrm{H}_{2} \mathrm{O}$, PBS and Dulbecco's modified Eagle medium (DMEM) for 5 days (Fig. S6). The X-ray photoelectron spectroscopy (XPS) results are shown in Fig. $1 \mathrm{j}$ and $\mathrm{k}$. The two peaks located at 87.77 and $84.03 \mathrm{eV}$ were assigned to $A u 4 f_{5 / 2}$ and $4 f_{7 / 2}$ (Fig. 1j) [40], and those at 653.63 and $641.87 \mathrm{eV}$ were attributed to Mn (IV) $2 \mathrm{p}_{1 / 2}$ and $\mathrm{Mn}$ (IV) $2 \mathrm{p}_{3 / 2}$, respectively (Fig. 1k) [41]. All these results confirmed the formation of COF-Au- $\mathrm{MnO}_{2}$.

Under slightly acidic conditions, $\mathrm{MnO}_{2}$ will react with $\mathrm{H}_{2} \mathrm{O}_{2}$ to produce $\mathrm{O}_{2}$ [17]. To mimic the TME, the dissolved oxygen was measured at $\mathrm{pH} 6.45$ by using a dissolved oxygen meter. By injecting COF-Au- $\mathrm{MnO}_{2}$ into the $\mathrm{H}_{2} \mathrm{O}_{2}$ solution with a concentration of $100 \times$ $10^{-6} \mathrm{~mol} \mathrm{~L}^{-1}$, the concentration of dissolved $\mathrm{O}_{2}$ increased rapidly, which suggested that $\mathrm{COF}-\mathrm{Au}-\mathrm{MnO}_{2}$ could decompose $\mathrm{H}_{2} \mathrm{O}_{2}$ to produce $\mathrm{O}_{2}$ through the reaction between $\mathrm{H}_{2} \mathrm{O}_{2}$ and $\mathrm{MnO}_{2}$ in the presence of $\mathrm{H}^{+}$[42]. It should be noted that the concentration of dissolved $\mathrm{O}_{2}$ 

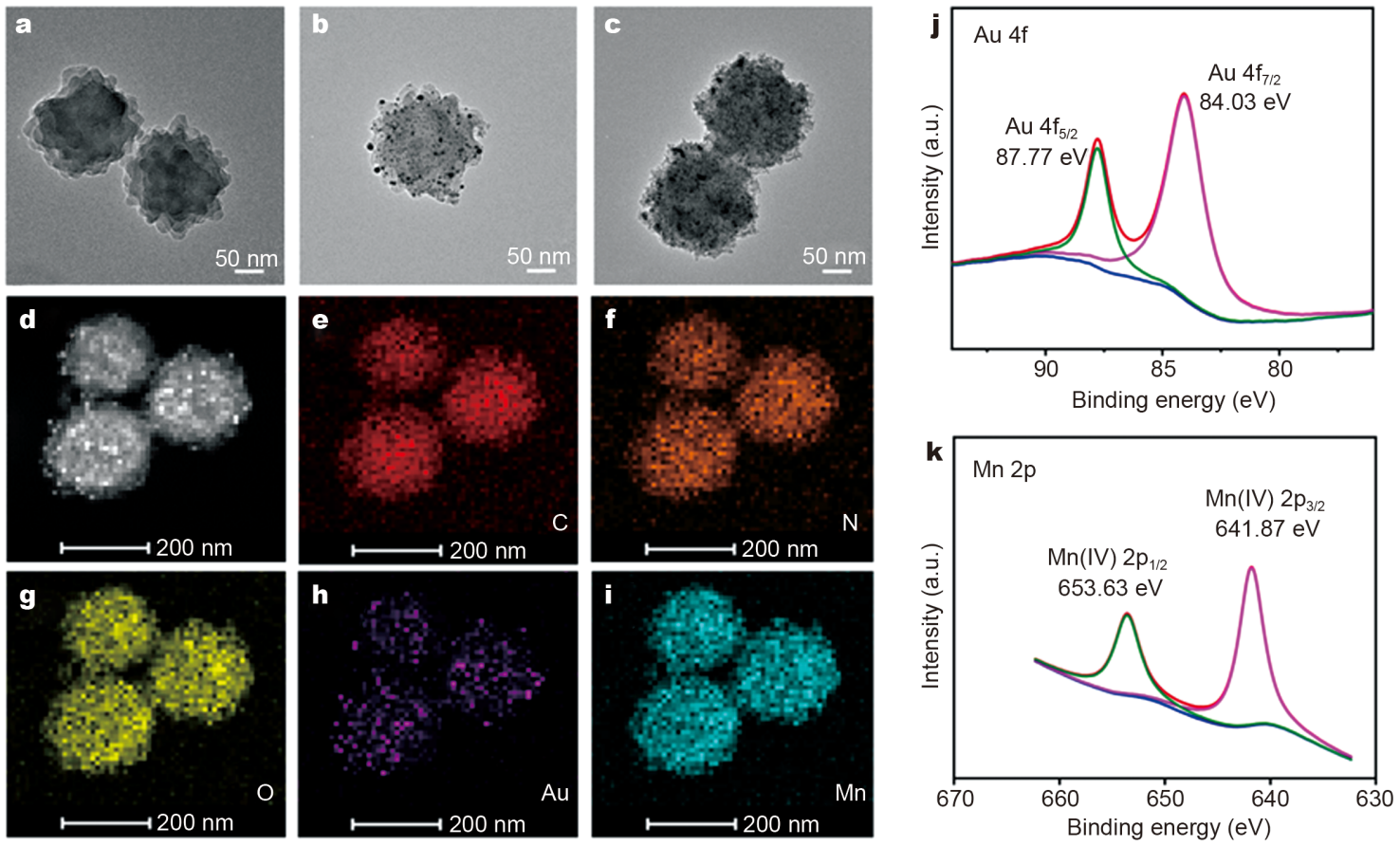

Figure 1 Characterization of COF-Au- $\mathrm{MnO}_{2}$. TEM images of (a) COF, (b) COF-Au, and (c) COF-Au- $\mathrm{MnO}_{2}$ nanoparticles. (d-i) The elemental mapping results of COF-Au- $\mathrm{MnO}_{2}$. High-resolution XPS spectra of (j) Au 4f, and (k) Mn 2p.

increased much more by further introducing glucose (Fig. 2a). Such a phenomenon also indicated that the oxidation reaction of glucose can promote the generation of oxygen. Meanwhile, the dissolved oxygen content did not increase when GSH was added. Additionally, the GOx-like activity of Au NPs was investigated. Au NPs were capable of catalyzing the oxidation of glucose and producing gluconic acid (GA) and hydrogen peroxide in the presence of $\mathrm{O}_{2}$ [43]. As the concentration of the COF$\mathrm{Au}$ NPs increased, the amount of $\mathrm{H}_{2} \mathrm{O}_{2}$ produced in the glucose solution also increased (Fig. 2b). The GA was then detected by using a GA-specific colorimetric assay in this study. Specifically, COF-Au NPs were incubated with glucose for different times, and then the supernatant was obtained by centrifugation. After addition of $\mathrm{Fe}^{3+}$ and hydroxylamine $\left(\mathrm{NH}_{2} \mathrm{OH}\right)$ into the supernatant, hydroxamate- $\mathrm{Fe}^{3+}$ was formed for GA in the solution and the intensity of the typical absorbance peak increased over time (Fig. S7) [12].

The type II PDT could kill cancer cells by using ${ }^{1} \mathrm{O}_{2}$, which will damage the DNA of tumor cells directly [34]. As shown in Fig. S8, a broad absorption band centered at around $460 \mathrm{~nm}$ was observed for the as-synthesized COF, and no obvious change was found after the incorporation of $\mathrm{Au}$ and $\mathrm{MnO}_{2}$. The ${ }^{1} \mathrm{O}_{2}$ generation ability under $650 \mathrm{~nm}$ laser irradiation was investigated through a ty- pical chemical probe, 1,3-diphenylisobenzofuran (DPBF) [33]. The decrease of the absorption intensity at around $410 \mathrm{~nm}$ indicated the degradation of DPBF, which also reflected the amount of ${ }^{1} \mathrm{O}_{2}$ produced. Almost no change was found for the intensity of the characteristic peak of DPBF under $650 \mathrm{~nm}$ laser irradiation for $12 \mathrm{~min}$, suggesting that no ROS was generated for DPBF under $650 \mathrm{~nm}$ laser irradiation (Fig. S9). As shown in Fig. 2c and $\mathrm{d}$, after adding $\mathrm{H}_{2} \mathrm{O}_{2}$, the ability to produce ${ }^{1} \mathrm{O}_{2}$ of COF-Au- $\mathrm{MnO}_{2}$ has been greatly enhanced due to the increased $\mathrm{O}_{2}$ generation [42]. The ${ }^{1} \mathrm{O}_{2}$ generation capability of COF-Au- $\mathrm{MnO}_{2}$ was also evaluated by the electron spin resonance (ESR) test with 2,2,6,6-tetramethylpiperidine (TEMP) as the ${ }^{1} \mathrm{O}_{2}$ trapper. As shown in Fig. S10, the characteristic ${ }^{1} \mathrm{O}_{2}$-induced signals upon $650 \mathrm{~nm}$ laser irradiation $\left(0.5 \mathrm{~W} \mathrm{~cm}^{-2}, 10 \mathrm{~min}\right)$ were observed for COF-Au- $\mathrm{MnO}_{2}$ solution, and the intensity increased in the presence of $\mathrm{H}_{2} \mathrm{O}_{2}$. Meanwhile, the temperature of COF-Au- $\mathrm{MnO}_{2}$ aqueous solution did not increase obviously under $650 \mathrm{~nm}$ laser irradiation. Therefore, the photothermal effect of COF-Au- $\mathrm{MnO}_{2}$ under $650 \mathrm{~nm}$ laser irradiation is negligible (Fig. S11). The photodynamic effect was further investigated under normoxic and hypoxic environments, respectively (Fig. 2e and $\mathrm{f}$ ). The phenomenon was similar, and compared with $\mathrm{COF}$, the photodynamic effect of $\mathrm{COF}-\mathrm{Au}-\mathrm{MnO}_{2}$ was 

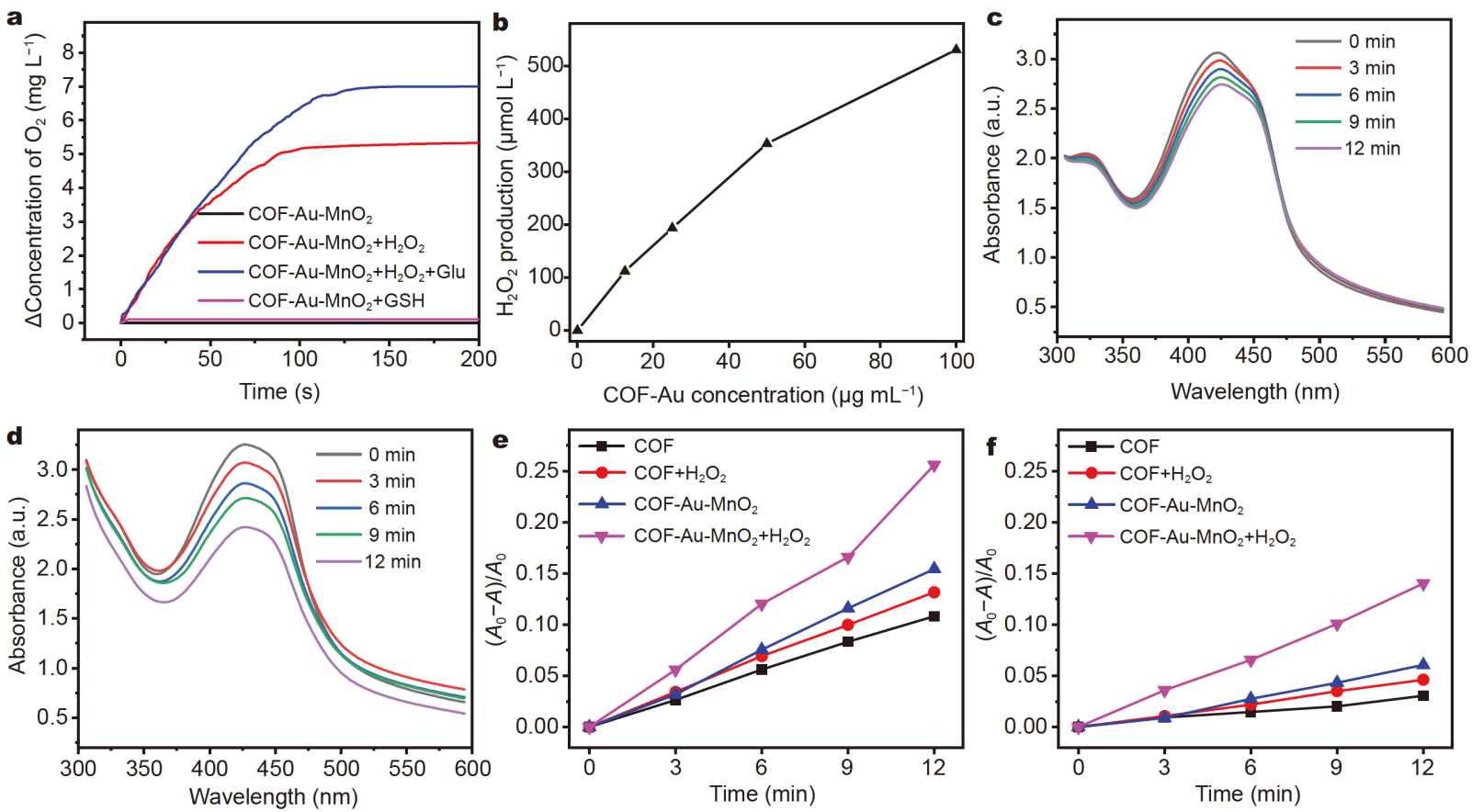

Figure 2 (a) $\mathrm{O}_{2}$ generation in $\mathrm{pH} 6.45$ solution with different samples. (b) $\mathrm{H}_{2} \mathrm{O}_{2}$ production with different concentrations of COF-Au. UV-vis absorption curves of DPBF solution treated with (c) COF-Au- $\mathrm{MnO}_{2}+650 \mathrm{~nm}$ laser, and (d) $\mathrm{COF}-\mathrm{Au}-\mathrm{MnO}_{2}+\mathrm{H}_{2} \mathrm{O}_{2}+650 \mathrm{~nm}$ laser. PDT effects of the samples irradiated under (e) normoxic and (f) hypoxic environments, respectively.

greatly enhanced in the presence of $\mathrm{H}_{2} \mathrm{O}_{2}$, which should be attributed to the decomposition of $\mathrm{H}_{2} \mathrm{O}_{2}$ and generation of ${ }^{1} \mathrm{O}_{2}$ by COF-Au- $\mathrm{MnO}_{2}$. Therefore, COF-Au$\mathrm{MnO}_{2}$ can indeed relieve hypoxia in the presence of $\mathrm{H}_{2} \mathrm{O}_{2}$ and thus improve the photodynamic effect under laser irradiation. The ability for COF-Au- $\mathrm{MnO}_{2}$ to deplete GSH was further confirmed with a UV spectrophotometer measurement (Fig. S12) [44].

The ROS generated in cells was tested by using 2,7dichlorodi-hydrofluorescein diacetate (DCFH-DA) as an indicator [34,45]. As shown in Fig. 3a, under normoxic environment, the $4 \mathrm{~T} 1$ cells incubated with COF-HA and COF-Au- $\mathrm{MnO}_{2}-\mathrm{HA}$ both showed green fluorescence after irradiation by a $650 \mathrm{~nm}$ laser. However, under hypoxic environment $\left(1 \% \mathrm{O}_{2}, 5 \% \mathrm{CO}_{2}\right.$, and $\left.94 \% \mathrm{~N}_{2}\right)$ [42], only the cells incubated with $\mathrm{COF}-\mathrm{Au}-\mathrm{MnO}_{2}-\mathrm{HA}$ could produce fluorescence under laser irradiation, which also indicated that $\mathrm{COF}-\mathrm{Au}-\mathrm{MnO}_{2}-\mathrm{HA}$ could relieve hypoxia efficiently. Subsequently, the cellular uptake process was investigated. As shown in Fig. S13, the red emission for the rhodamine $\mathrm{B}(\mathrm{RhB})$-conjugated $\mathrm{COF}-\mathrm{Au}-\mathrm{MnO}_{2}-\mathrm{HA}$ became stronger as the culture time increased, suggesting the effective endocytosis of the materials [29].

The hypoxia probe $\left[\mathrm{Ru}(\mathrm{dpp})_{3}\right] \mathrm{Cl}_{2}(\mathrm{RDPP})$ was used in this study to measure the generated $\mathrm{O}_{2}$ for COF-Au-
$\mathrm{MnO}_{2}$-HA NPs, as the fluorescence of RDPP will be strongly quenched in the presence of $\mathrm{O}_{2}$ [46]. As shown in Fig. 3b, red fluorescence could be observed for the control and COF-HA-treated groups. In contrast, the intensity of red emission for the COF-Au- $\mathrm{MnO}_{2}-\mathrm{HA}$ group was obviously weakened, which indicated that $\mathrm{MnO}_{2}$ in COF-Au- $\mathrm{MnO}_{2}$-HA NPs could decompose endogenous $\mathrm{H}_{2} \mathrm{O}_{2}$ to produce $\mathrm{O}_{2}$ and the hypoxic condition would be alleviated after the NPs were internalized by the $4 \mathrm{~T} 1$ cells. It further demonstrated that the COF-Au$\mathrm{MnO}_{2}$ NPs could overcome tumor hypoxia efficiently. The degradation of glutathione at the cellular level was then measured. $4 \mathrm{~T} 1$ cells were cultured with different concentrations of COF-Au- $\mathrm{MnO}_{2}-\mathrm{HA}$ for about $24 \mathrm{~h}$, then the GSH assay kit was used to detect the content of intracellular GSH (Fig. 3c). As the concentration of COF$\mathrm{Au}-\mathrm{MnO}_{2}$-HA increased, the content of GSH was reduced dramatically, suggesting the efficient depletion of GSH by COF-Au- $\mathrm{MnO}_{2}$-HA [44].

The biocompatibility of COF-HA and COF-Au- $\mathrm{MnO}_{2}-$ $\mathrm{HA}$ was evaluated through the standard methyl thiazolyl tetrazolium (MTT) assay [31]. As shown in Fig. 3d, the survival rate of L929 cells was still over $80 \%$ even at a high concentration of $200 \mu \mathrm{g} \mathrm{mL}{ }^{-1}$, revealing the good biocompatibility of COF-HA and COF-Au- $\mathrm{MnO}_{2}-\mathrm{HA}$. The 

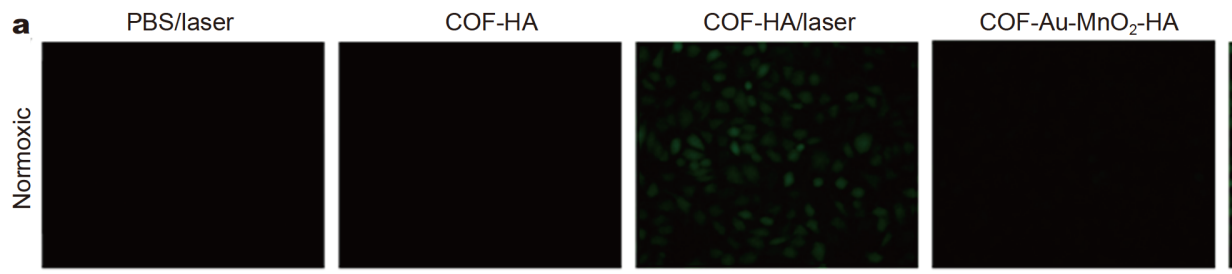

COF-Au- $\mathrm{MnO}_{2}-\mathrm{HA} / \mathrm{laser}$
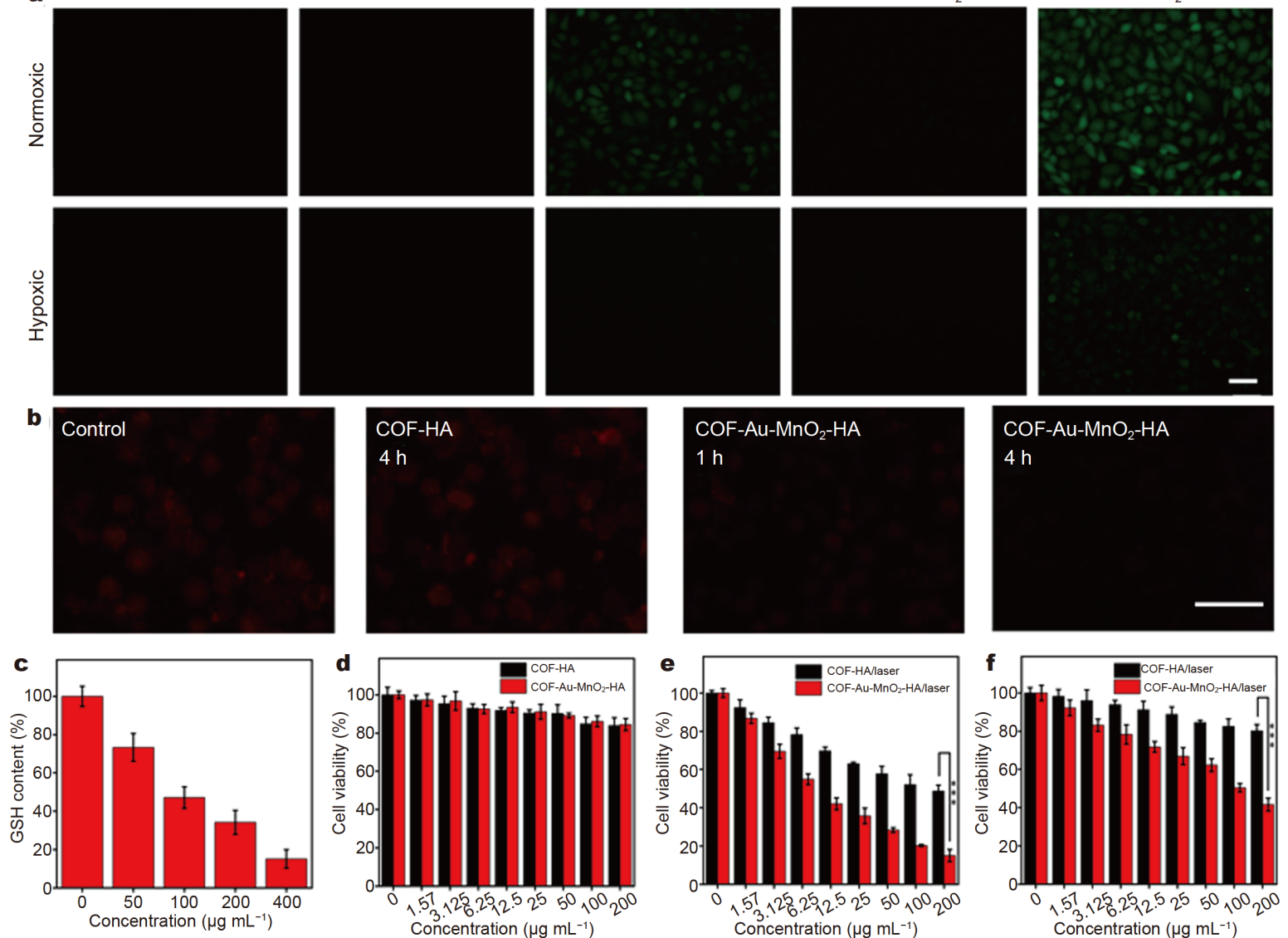

Figure 3 (a) The inverted fluorescence microscopy images of DCFH-DA in 4T1 cells under different conditions. (b) The inverted fluorescence microscopy images of RDPP in $4 \mathrm{~T} 1$ cells under different conditions. (c) Intracellular GSH depletion with different concentrations of $\mathrm{COF}$-Au- $\mathrm{MnO}_{2}-$

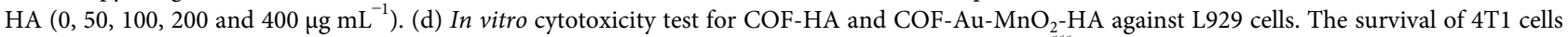
with COF-HA/laser and COF-Au-MnO $2-\mathrm{HA} /$ laser in (e) normoxic and (f) hypoxic environments, $p<0.001$. Scale bar is $20 \mu \mathrm{m}$.

photodynamic effect in vitro under normoxic and hypoxic environments was further tested through MTT assay and cell apoptosis measurement. For the MTT test, under normoxic environment, both COF-HA and COF$\mathrm{Au}-\mathrm{MnO}_{2}-\mathrm{HA}$ exhibited excellent photodynamic effect, and the mortality rate of $4 \mathrm{~T} 1$ cells treated with $200 \mu \mathrm{g} \mathrm{mL}^{-1}$ of COF-Au- $\mathrm{MnO}_{2}-\mathrm{HA}$ was almost $80 \%$, which was higher than that of the COF-HA-treated cells (50\%, Fig. 3e). However, under hypoxic condition, no obvious cytotoxicity was found for the COF-HA-treated $4 \mathrm{~T} 1$ cells under $650 \mathrm{~nm}$ laser irradiation, but the cell viability was decreased to about $50 \%$ for the COF-Au$\mathrm{MnO}_{2}$-HA-treated group at a concentration of $200 \mu \mathrm{g} \mathrm{mL}^{-1}$ (Fig. 3f). Therefore, the photodynamic effect is largely limited by the oxygen content. Moreover, the cell apoptosis was investigated by flow cytometric analysis through the annexin V-fluorescein isothiocyanate
(FITC)/propidium iodide (PI) apoptosis detection kit under normoxic and hypoxic environments, respectively (Figs S14 and S15) [34]. Under normoxic environment, the cell apoptosis of $\mathrm{COF}-\mathrm{Au}-\mathrm{MnO}_{2}-\mathrm{HA}+$ laser group was $24.0 \%$, which was higher than that of the COF+laser group (17.9\%), consistent with the MTT result. Nevertheless, under hypoxic environment, only the COF-Au$\mathrm{MnO}_{2}-\mathrm{HA}+$ laser group had an apoptotic rate of $15.2 \%$, and no obvious damages were observed for the other groups. Therefore, it is further demonstrated that COF$\mathrm{Au}-\mathrm{MnO}_{2}-\mathrm{HA}$ can enhance the photodynamic effect under hypoxic environment.

$\mathrm{Mn}^{2+}$ is an excellent $T_{1}$ MRI contrast agent owing to its unique molecular orbital, and in this study, $\mathrm{Mn}^{2+}$ could be released through the decomposition of $\mathrm{MnO}_{2}$ by GSH inside the tumor [47-49]. As shown in Fig. 4a, due to the five unpaired $3 \mathrm{~d}$ electrons of $\mathrm{Mn}^{2+}$, the longitudinal re- 

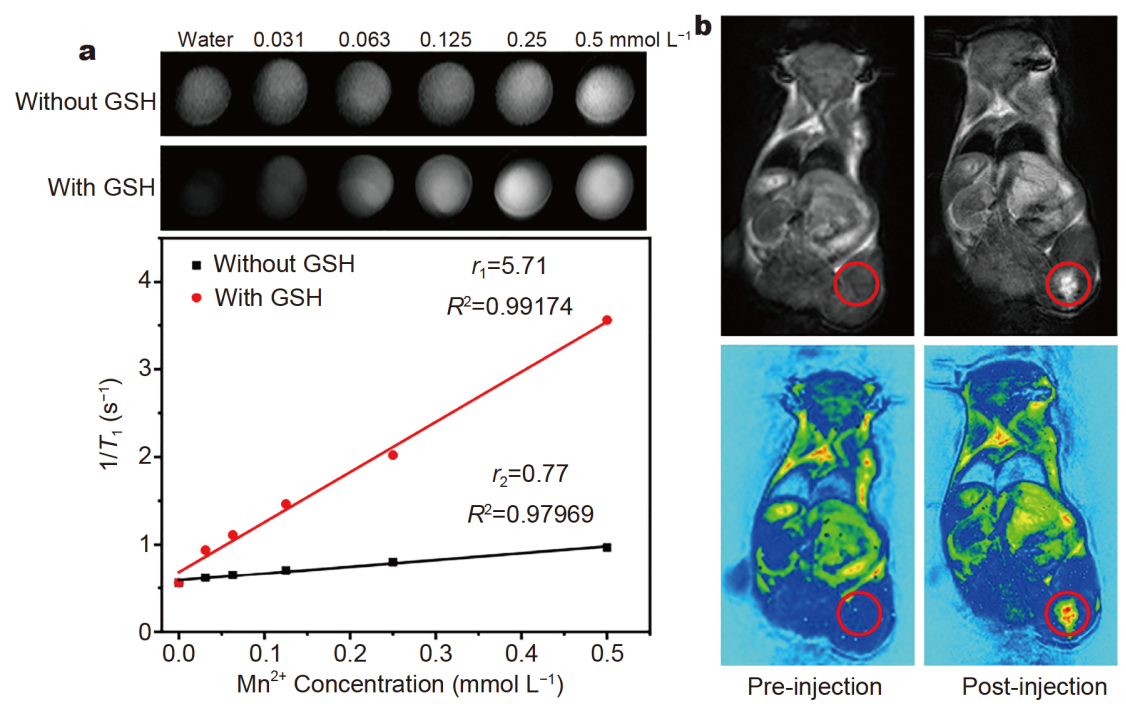

Figure 4 (a) In vitro $T_{1}$-weighted $\mathrm{MRI}$ of $\mathrm{COF}-\mathrm{Au}-\mathrm{MnO}_{2}$ recorded using $1.2 \mathrm{~T}$ MRI scanner at different concentrations of $\mathrm{Mn}$ with or without excessive GSH treatment and the corresponding relaxation rate $r_{1}$ versus the concentration of $\mathrm{Mn}^{2+}$. (b) In vivo $T_{1}$-weighted MRI of tumor-bearing mice before and after injection of $\mathrm{COF}-\mathrm{Au}-\mathrm{MnO}_{2}-\mathrm{HA}$. Tumor positions are marked by red circles.
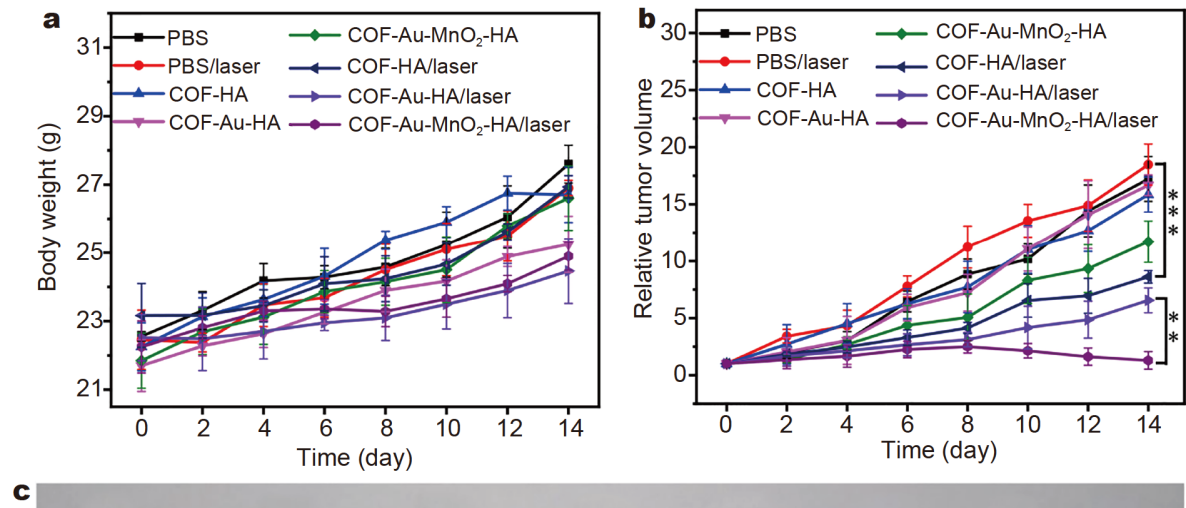

(4)

(5)

(6)

(7)

(8)
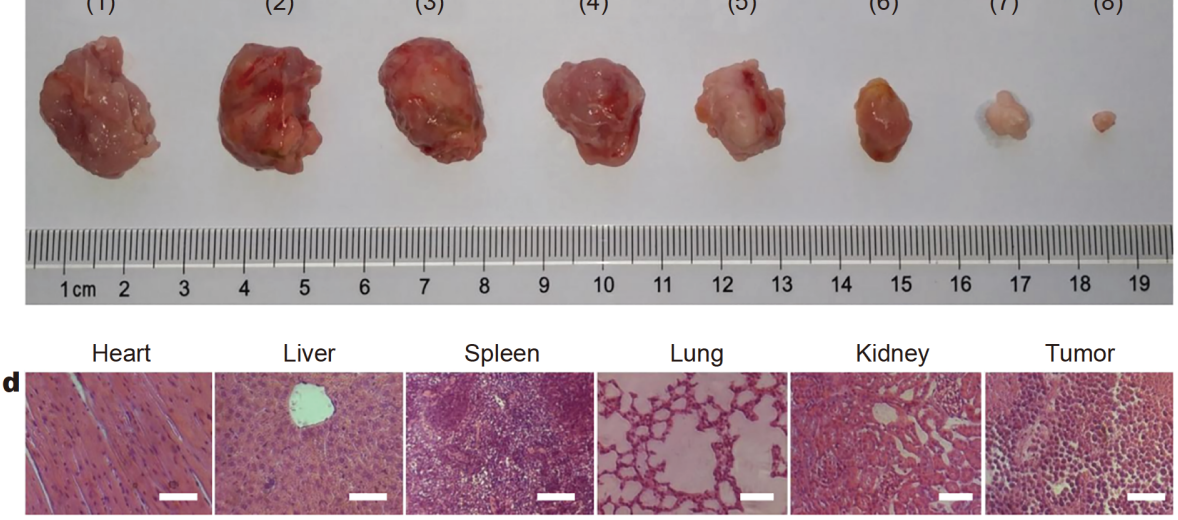

Figure 5 (a) Body weight and (b) relative tumor volumes of mice treated with different methods, ${ }^{* * *} p<0.001,{ }^{* *} p<0.01$. (c) Representative photographs of tumors for all groups on the last day of treatment. (d) $\mathrm{H} \& \mathrm{E}$ stained images of major organs and tumor slices of mice for $\mathrm{COF}_{-} \mathrm{Au}-\mathrm{MnO}_{2}-$ $\mathrm{HA}$ /laser-treated group. (1) PBS, (2) PBS under $650 \mathrm{~nm}$ laser irradiation, (3) COF-HA, (4) COF-Au-HA, (5) COF-Au-MnO $2-\mathrm{HA}$, (6) COF-HA under $650 \mathrm{~nm}$ laser irradiation, (7) COF-Au-HA under $650 \mathrm{~nm}$ laser irradiation, and (8) COF-Au- $\mathrm{MnO}_{2}-\mathrm{HA}$ under $650 \mathrm{~nm}$ laser irradiation. Scale bar is $20 \mu \mathrm{m}$. 
laxivity $\left(r_{1}\right)$ of GSH-treated group was $5.71 \mathrm{~L} \mathrm{mmol}^{-1} \mathrm{~s}^{-1}$, which was much higher than that of the untreated group $\left(0.77 \mathrm{~L} \mathrm{mmol}^{-1} \mathrm{~s}^{-1}\right)$ [49]. For the in vivo $T_{1}$-weighted MRI test, the relative intensity at the tumor site of the $4 \mathrm{~T} 1$ tumor-bearing $\mathrm{BALB} / \mathrm{c}$ mouse was significantly enhanced after in-situ injection of COF-Au- $\mathrm{MnO}_{2}$-HA (Fig. 4b).

The in vivo experiments were finally performed to verify the antitumor efficacy of COF-Au- $\mathrm{MnO}_{2}[3,29,34]$. The $4 \mathrm{~T} 1$ tumor-bearing $\mathrm{BALB} / \mathrm{c}$ mice with an average tumor volume of $100 \mathrm{~mm}^{3}$ were randomly divided into eight groups ( $n=6$, per group) and treated with different ways: (1) PBS, (2) PBS under $650 \mathrm{~nm}$ laser irradiation, (3) COF-HA, (4) COF-Au-HA, (5) COF-Au- $\mathrm{MnO}_{2}-\mathrm{HA}$, (6) COF-HA under $650 \mathrm{~nm}$ laser irradiation, (7) COF-Au$\mathrm{HA}$ under $650 \mathrm{~nm}$ laser irradiation, and (8) COF-Au$\mathrm{MnO}_{2}$-HA under $650 \mathrm{~nm}$ laser irradiation. It was found from Fig. 5a that the weights of mice for the eight groups steadily increased during the treatment, suggesting the great in vivo biocompatibility of the materials $[6,20,21]$. As shown in Fig. $5 b$ and $c$, the relative tumor volume of groups (1)-(5) increased rapidly; however, upon laser irradiation, the groups (6)-(8) all had a certain therapeutic effect, and the best antitumor efficacy was achieved for the group (8) due to the enhanced PDT by efficient relieving hypoxia. No significant damages to the major organs and obvious lesions to the tumors were observed for the hematoxylin and eosin (H\&E) staining images (Fig. 5d) [9,31].

\section{CONCLUSIONS}

A multifunctional therapeutic platform based on COF$\mathrm{Au}-\mathrm{MnO}_{2}$ was synthesized. The resultant COF-Au- $\mathrm{MnO}_{2}$ could catalyze endogenous $\mathrm{H}_{2} \mathrm{O}_{2}$ to produce $\mathrm{O}_{2}$ and consume GSH to enhance the $\mathrm{O}_{2}$-dependent PDT, and the generated $\mathrm{O}_{2}$ could also facilitate the decomposition of glucose by Au NPs. At the same time, the starving-like therapy can in turn promote the catalytic efficiency of $\mathrm{MnO}_{2}$ and form cycle-like cascade reactions. The in vitro and in vivo experiments confirmed the excellent cancer cell killing effect and antitumor efficacy of COF-Au$\mathrm{MnO}_{2}$ on account of the combination of relieving intratumoral hypoxia, enhancement of PDT and starvationlike therapy. This study further demonstrated the excellent biomedical application of COF, especially by using TME to conduct the catalytic cascade reactions, and also provides an approach to construct COF-based therapeutic platform for cancer treatment.

Received 6 May 2020; accepted 11 June 2020; published online 7 September 2020
1 Maman S, Witz IP. A history of exploring cancer in context. Nat Rev Cancer, 2018, 18: 359-376

2 Gould CM, Courtneidge SA. Regulation of invadopodia by the tumor microenvironment. Cell Adhes Migration, 2014, 8: 226-235

3 Wang $\mathrm{H}$, Han X, Dong Z, et al. Hyaluronidase with $\mathrm{pH}$-responsive dextran modification as an adjuvant nanomedicine for enhanced photodynamic-immunotherapy of cancer. Adv Funct Mater, 2019, 29: 1902440

4 Ma B, Wang S, Liu F, et al. Self-assembled copper-amino acid nanoparticles for in situ glutathione "AND" $\mathrm{H}_{2} \mathrm{O}_{2}$ sequentially triggered chemodynamic therapy. J Am Chem Soc, 2018, 141: 849857

5 Tian H, Luo Z, Liu L, et al. Cancer cell membrane-biomimetic oxygen nanocarrier for breaking hypoxia-induced chemoresistance. Adv Funct Mater, 2017, 27: 1703197

6 Tian Q, Li Y, Jiang S, et al. Tumor pH-responsive albumin/polyaniline assemblies for amplified photoacoustic imaging and augmented photothermal therapy. Small, 2019, 15: 1902926

7 Tang Z, Liu Y, He M, et al. Chemodynamic therapy: Tumour microenvironment-mediated Fenton and Fenton-like reactions. Angew Chem Int Ed, 2019, 58: 946-956

8 Lin $\mathrm{H}$, Chen Y, Shi J. Nanoparticle-triggered in situ catalytic chemical reactions for tumour-specific therapy. Chem Soc Rev, 2018, 47: 1938-1958

9 Zhang Y, Wang F, Liu C, et al. Nanozyme decorated metal-organic frameworks for enhanced photodynamic therapy. ACS Nano, 2018, 12: 651-661

10 Gao S, Lin $\mathrm{H}$, Zhang $\mathrm{H}$, et al. Nanocatalytic tumor therapy by biomimetic dual inorganic nanozyme-catalyzed cascade reaction. Adv Sci, 2019, 6: 1801733

11 Fan J, Yin JJ, Ning B, et al. Direct evidence for catalase and peroxidase activities of ferritin-platinum nanoparticles. Biomaterials, 2011, 32: 1611-1618

12 Zhang L, Pan J, Long Y, et al. $\mathrm{CeO}_{2}$-encapsulated hollow Ag-Au nanocage hybrid nanostructures as high-performance catalysts for cascade reactions. Small, 2019, 15: 1903182

13 Kotov NA. Inorganic nanoparticles as protein mimics. Science, 2010, 330: 188-189

14 Comotti M, Della Pina C, Matarrese R, et al. The catalytic activity of "naked" gold particles. Angew Chem Int Ed, 2004, 43: 58125815

15 Yao C, Wang W, Wang P, et al. Near-infrared upconversion mesoporous cerium oxide hollow biophotocatalyst for concurrent $\mathrm{pH}-/ \mathrm{H}_{2} \mathrm{O}_{2}$-responsive $\mathrm{O}_{2}$-evolving synergetic cancer therapy. Adv Mater, 2018, 30: 1704833

16 Yang G, Xu L, Chao Y, et al. Hollow $\mathrm{MnO}_{2}$ as a tumor-microenvironment-responsive biodegradable nano-platform for combination therapy favoring antitumor immune responses. Nat Commun, 2017, 8: 902

17 Ding $\mathrm{B}$, Shao S, Jiang $\mathrm{F}$, et al. $\mathrm{MnO}_{2}$-disguised upconversion hybrid nanocomposite: An ideal architecture for tumor microenvironment-triggered UCL/MR bioimaging and enhanced chemodynamic therapy. Chem Mater, 2019, 31: 2651-2660

18 Liu $\mathrm{Y}$, Jiang $\mathrm{Y}$, Zhang $\mathrm{M}$, et al. Modulating hypoxia via nanomaterials chemistry for efficient treatment of solid tumors. Acc Chem Res, 2018, 51: 2502-2511

19 Kim J, Cho HR, Jeon $\mathrm{H}$, et al. Continuous $\mathrm{O}_{2}$-evolving $\mathrm{MnFe}_{2} \mathrm{O}_{4}$ nanoparticle-anchored mesoporous silica nanoparticles for efficient photodynamic therapy in hypoxic cancer. J Am Chem Soc, 2017, 139: 10992-10995 
20 Liu J, Du P, Liu T, et al. A black phosphorus/manganese dioxide nanoplatform: Oxygen self-supply monitoring, photodynamic therapy enhancement and feedback. Biomaterials, 2019, 192: 179188

21 Ding B, Zheng P, Ma P, et al. Manganese oxide nanomaterials: Synthesis, properties, and theranostic applications. Adv Mater, 2020, 32: 1905823

22 He M, Chen Y, Tao C, et al. Mn-porphyrin-based metal-organic framework with high longitudinal relaxivity for magnetic resonance imaging guidance and oxygen self-supplementing photodynamic therapy. ACS Appl Mater Interfaces, 2019, 11: 4194641956

23 Zhang L, Wang S, Zhou Y, et al. Covalent organic frameworks as favorable constructs for photodynamic therapy. Angew Chem, 2019, 131: 14351-14356

24 Segura JL, Royuela S, Mar Ramos M. Post-synthetic modification of covalent organic frameworks. Chem Soc Rev, 2019, 48: 39033945

25 Xiang Z, Mercado R, Huck JM, et al. Systematic tuning and multifunctionalization of covalent organic polymers for enhanced carbon capture. J Am Chem Soc, 2015, 137: 13301-13307

26 Mitra S, Sasmal HS, Kundu T, et al. Targeted drug delivery in covalent organic nanosheets (CONs) via sequential postsynthetic modification. J Am Chem Soc, 2017, 139: 4513-4520

27 Zhang G, Li X, Liao Q, et al. Water-dispersible PEG-curcumin/ amine-functionalized covalent organic framework nanocomposites as smart carriers for in vivo drug delivery. Nat Commun, 2018, 9: 2785

28 Gan S, Tong X, Zhang Y, et al. Covalent organic frameworksupported molecularly dispersed near-infrared dyes boost immunogenic phototherapy against tumors. Adv Funct Mater, 2019, 29: 1902757

29 Liu S, Hu C, Liu Y, et al. One-pot synthesis of DOX@covalent organic framework with enhanced chemotherapeutic efficacy. Chem Eur J, 2019, 25: 4315-4319

30 Mi Z, Yang P, Wang R, et al. Stable radical cation-containing covalent organic frameworks exhibiting remarkable structureenhanced photothermal conversion. J Am Chem Soc, 2019, 141: $14433-14442$

31 Shi Y, Liu S, Zhang Z, et al. Template-free synthesis and metalation of hierarchical covalent organic framework spheres for photothermal therapy. Chem Commun, 2019, 55: 14315-14318

32 Guan Q, Zhou LL, Li YA, et al. Nanoscale covalent organic framework for combinatorial antitumor photodynamic and photothermal therapy. ACS Nano, 2019, 13: 13304-13316

$33 \mathrm{Hu} \mathrm{C}$, Zhang Z, Liu S, et al. Monodispersed CuSe sensitized covalent organic framework photosensitizer with an enhanced photodynamic and photothermal effect for cancer therapy. ACS Appl Mater Interfaces, 2019, 11: 23072-23082

$34 \mathrm{Hu}$ C, Cai L, Liu S, et al. Integration of a highly monodisperse covalent organic framework photosensitizer with cation exchange synthesized $\mathrm{Ag}_{2} \mathrm{Se}$ nanoparticles for enhanced phototherapy. Chem Commun, 2019, 55: 9164-9167

35 Choi KY, Han HS, Lee ES, et al. Hyaluronic acid-based activatable nanomaterials for stimuli-responsive imaging and therapeutics: Beyond CD44-mediated drug delivery. Adv Mater, 2019, 31: 1803549

36 Chu PY, Tsai SC, Ko HY, et al. Co-delivery of natural compounds with a dual-targeted nanoparticle delivery system for improving synergistic therapy in an orthotopic tumor model. ACS Appl Mater
Interfaces, 2019, 11: 23880-23892

37 Wang $\mathrm{M}, \mathrm{Hou} \mathrm{Z}$, Al Kheraif AA, et al. Mini review of $\mathrm{TiO}_{2}$-based multifunctional nanocomposites for near-infrared light-responsive phototherapy. Adv Healthcare Mater, 2018, 7: 1800351

38 Zhou J, Li M, Hou Y, et al. Engineering of a nanosized biocatalyst for combined tumor starvation and low-temperature photothermal therapy. ACS Nano, 2018, 12: 2858-2872

39 Fang Q, Wang J, Gu S, et al. 3D porous crystalline polyimide covalent organic frameworks for drug delivery. J Am Chem Soc, 2015, 137: 8352-8355

40 Li Z, Yang X, Yang Y, et al. Peroxidase-mimicking nanozyme with enhanced activity and high stability based on metal-support interactions. Chem Eur J, 2018, 24: 409-415

41 Luo Y, Jiang J, Zhou W, et al. Self-assembly of well-ordered whisker-like manganese oxide arrays on carbon fiber paper and its application as electrode material for supercapacitors. J Mater Chem, 2012, 22: 8634-8640

42 Liu C, Xing J, Akakuru OU, et al. Nanozymes-engineered metalorganic frameworks for catalytic cascades-enhanced synergistic cancer therapy. Nano Lett, 2019, 19: 5674-5682

43 Rakitzis ET, Papandreou P. Reactivity of 6-phosphogluconolactone with hydroxylamine: The possible involvement of glucose-6phosphate dehydrogenase in endogenous glycation reactions. Chemico-Biol Interactions, 1998, 113: 205-216

44 Chang $M$, Wang $M$, Wang $M$, et al. A multifunctional cascade bioreactor based on hollow-structured $\mathrm{Cu}_{2} \mathrm{MoS}_{4}$ for synergetic cancer chemo-dynamic therapy/starvation therapy/phototherapy/ immunotherapy with remarkably enhanced efficacy. Adv Mater, 2019, 31: 1905271

45 Ding $\mathrm{B}$, Shao $\mathrm{S}$, Xiao $\mathrm{H}$, et al. $\mathrm{MnFe}_{2} \mathrm{O}_{4}$-decorated large-pore mesoporous silica-coated upconversion nanoparticles for nearinfrared light-induced and $\mathrm{O}_{2}$ self-sufficient photodynamic therapy. Nanoscale, 2019, 11: 14654-14667

46 Sun Q, Wang Z, Liu B, et al. Self-generation of oxygen and simultaneously enhancing photodynamic therapy and MRI effect: An intelligent nanoplatform to conquer tumor hypoxia for enhanced phototherapy. Chem Eng J, 2020, 390: 124624

47 Zhao Z, Fan H, Zhou G, et al. Activatable fluorescence/MRI bimodal platform for tumor cell imaging via $\mathrm{MnO}_{2}$ nanosheetaptamer nanoprobe. J Am Chem Soc, 2014, 136: 11220-11223

48 Lin LS, Song J, Song L, et al. Simultaneous Fenton-like ion delivery and glutathione depletion by $\mathrm{MnO}_{2}$-based nanoagent to enhance chemodynamic therapy. Angew Chem Int Ed, 2018, 57: 4902-4906

49 He D, Hai L, He X, et al. Glutathione-activatable and $\mathrm{O}_{2} / \mathrm{Mn}^{2+}$ evolving nanocomposite for highly efficient and selective photodynamic and gene-silencing dual therapy. Adv Funct Mater, 2017, 27: 1704089

Acknowledgements This work was supported by the National Natural Science Foundation of China (21471145), the Science and Technology Development Planning Project of Jilin Province (20170101179JC), and the "Hundred Talents Program" of Chinese Academy of Sciences.

Author contributions Pang M put forward the research ideas. Cai L performed the experiments. Hu C, Liu S and Zhou Y performed part of the experiments. Cai L wrote the paper with support from Pang $M$ and Lin J. All authors contributed to the general discussion.

Conflict of interest The authors declare that they have no conflict of interest. 
Supplementary information Experimental details and supporting data are available in the online version of the paper.

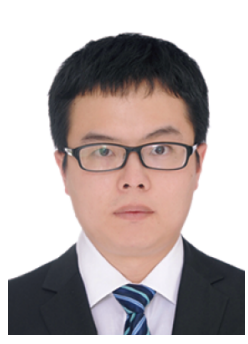

Lihan Cai is a master candidate at the University of Science and Technology of China. His current research focuses on the controllable preparation of covalent organic framework and its biomedical application.

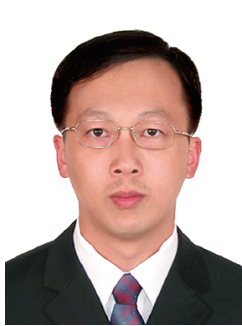

Maolin Pang obtained his BSc degree from the Northeast Normal University in 2000 and $\mathrm{PhD}$ degree from Changchun Institute of Applied Chemistry (CIAC), Chinese Academy of Sciences (CAS), in 2005. After graduation, he worked as postdoctoral fellow at Osaka University (JSPS), National University of Singapore, and King Abdullah University of Science and Technology, respectively. In 2014, he joined CIAC as a full professor, and was selected as a member of the "Hundred Talents Program" of the CAS in 2015. His research mainly focuses on the synthesis of micro- or nano-sized porous materials and investigation of their potential application in catalysis and biomedical fields.

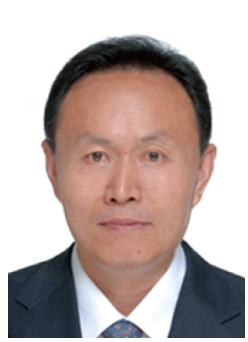

Jun Lin received his BSc and MSc degrees in inorganic chemistry from Jilin University in 1989 and 1992, respectively, and a $\mathrm{PhD}$ degree (inorganic chemistry) from CIAC, CAS, in 1995 . He worked as a postdoctoral researcher for more than 4 years at the City University of Hong Kong (1996), Institute of New Materials (Germany, 1997), Virginia Commonwealth University (USA, 1998), and University of New Orleans (USA, 1999). He is a professor at CIAC, CAS. His research interests include luminescent materials and multifunctional composite materials toward their applications in display, lighting and biomedical fields.
一种基于共价有机框架的多功能治疗平台通过催 化级联反应增强光动力治疗

蔡砺寒 ${ }^{1,2}$, 胡春玲 ${ }^{1,2}$, 刘赛男 ${ }^{1,2}$, 周莹 $^{1}$, 逢茂林 ${ }^{1,2^{*}}$, 林君 ${ }^{1,2,3^{*}}$

摘要 近年来, 利用肿瘤独特的微环境进行肿瘤治疗成为了热门研 究话题, 然而这种治疗方法经常受到诸多条件的限制, 如较少的反 应底物和较慢的反应速率, 反应所产生的毒性物质也不足以杀死 癌细胞等. 本文以共价有机骨架(COFs)为模板, 在表面生长金纳米 颗粒, 然后再包覆一层二氧化锰, 最后用透明质酸修饰以提高材料 的生物相容性. 最终得到的产物可以在肿瘤微环境中形成级联反 应: 在缺氧条件下, 二氧化锰可以分解肿瘤内部的过氧化氢产生氧 气以增强II型光动力疗法; 金纳米颗粒可以通过分解葡萄糖用于饥 饿疗法, 同时, 饥饿疗法所产生的过氧化氢又可以促进氧气的生成. 此外, 肿瘤内部的谷胱甘肽可以将二氧化锰分解为二价锰离子, 而 二价锰离子可以用于 $\mathrm{T}_{1}$ 加权 $\mathrm{MR}$ 成像. 最终体内和体外实验证明, 该 复合材料具有良好的癌细胞杀伤能力和抗肿瘤效果. 